\title{
Factors associated with alcohol use disorder: the role of depression, anxiety, stress, alexithymia and work fatigue- a population study in Lebanon
}

Sahar Obeid ${ }^{1,2,3}$, Marwan Akel ${ }^{3,4}$, Chadia Haddad ${ }^{1,5,6,7}$, Kassandra Fares ${ }^{2}$, Hala Sacre ${ }^{3,8}$, Pascale Salameh ${ }^{3,9,10+}$ and Souheil Hallit ${ }^{3,11^{*}}$ (i)

\begin{abstract}
Background: International research showed that common mental disorders such as depression, anxiety, social anxiety, stress, alexithymia and having insecure attachment styles are risk factors for alcohol use disorder (AUD). Our objective was to study the factors associated withAUD in a sample of the Lebanese population.

Methods: During the period lasting from November 2017 to March 2018, a sample of 789 Lebanese participants agreed to contribute to a cross-sectional study (53.23\% males). Alcohol use disorder was assessed using the Alcohol Use Disorder Identification Test (AUDIT).

Results: A high risk of AUD was associated with higher alexithymia (ORa $=1.030 ; \mathrm{Cl} 1.009-1.051)$, depression $(\mathrm{ORa}=1.076$; $\mathrm{Cl} 1.050-1.103)$ and suicidal ideation ( $\mathrm{ORa}=1.253 ; \mathrm{Cl} 1.026-1.531)$ in a significant manner. In opposition, a higher number of kids ( $\mathrm{ORa}=0.863 ; \mathrm{Cl} 0.752-0.991)$, being a female $(\mathrm{ORa}=0.460 ; \mathrm{Cl} 0.305-0.694)$ and higher emotional management $(\mathrm{ORa}=0.962 ; \mathrm{Cl} 0.937-0.988)$ were significantly associated with lower AUD risk.

A cluster analysis derived three mutually exclusive clusters. Cluster 1 formed $45.4 \%$ of the sample and assembled people with psychological difficulties (work fatigue and high stress, high emotional work fatigue and low emotional intelligence, low self-esteem, high social phobia, high alexithymia); Cluster 2 formed $34.4 \%$ of the sample and assembled people with high wellbeing (low suicidal ideation, low emotional work fatigue, depression and anxiety, high emotional intelligence, high self-esteem and low social phobia); whereas cluster 3 formed 20.2\% of the sample and represented people with mental dysfunction (high anxiety and depression, high suicidal ideation, low self-esteem and high social phobia, low emotional intelligence, high emotional work fatigue). People with psychological difficulties (cluster 1) (Beta $=5.547 ; \mathrm{Cl}$ 4.430-6.663), and people in distress (cluster 3) (Beta $=7.455$; Cl 5.945-8.965) were associated with higher AUDIT scores than those with high wellbeing (cluster 2).
\end{abstract}

Conclusion: AUD seems to be influenced by several factors among the Lebanese population, including alexithymia, stress, anxiety and work fatigue. Healthcare professionals should spread awareness to reduce the prevalence of these factors.

Keywords: Alcohol use disorder, Depression, Anxiety, Alexithymia, Self-esteem

\footnotetext{
* Correspondence: souheilhallit@hotmail.com

${ }^{\dagger}$ Pascale Salameh and Souheil Hallit are last co-authors

${ }^{3}$ INSPECT-LB: Institut National de Santé Publique, Epidémiologie Clinique et

Toxicologie - Liban, Beirut, Lebanon

${ }^{11}$ Faculty of Medicine and Medical Sciences, Holy Spirit University of Kaslik

(USEK), Jounieh, Lebanon

Full list of author information is available at the end of the article
}

(c) The Author(s). 2020 Open Access This article is distributed under the terms of the Creative Commons Attribution 4.0 International License (http://creativecommons.org/licenses/by/4.0/), which permits unrestricted use, distribution, and reproduction in any medium, provided you give appropriate credit to the original author(s) and the source, provide a link to the Creative Commons license, and indicate if changes were made. The Creative Commons Public Domain Dedication waiver (http://creativecommons.org/publicdomain/zero/1.0/) applies to the data made available in this article, unless otherwise stated. 


\section{Background}

Alcoholism, also known as alcohol use disorder (AUD), is a broad term for any drinking of alcohol that results in mental or physical health problems [1]. Alcohol use disorder is the third leading risk factor for the global burden of disease [2]. The prevalence of alcohol use disorder varies around the world, being highest in Northern and Eastern Europe [3] and parts of the Americas (8.4\% in adult men and $4.2 \%$ in adult women) [4], while the ranges observed in the Mediterranean countries vary between $1.7 \%$ [5] and $11.2 \%$ [6]. A study carried out in Lebanon showed that the 12-month alcoholism prevalence is $6.2 \%$ [7]. However, these numbers are expected to be an underestimation since alcohol consumption is prohibited by Islam and may be clandestine among Muslims [8].

In particular, studies in Lebanon have shown that alcohol consumption is a major public health problem among adolescents and young adults. Thus, a $40 \%$ increase in the alcohol consumption was seen among elementary students between 2005 and 2011, with 85\% having drunk their first glass of alcohol before the age of 14 [9]. In addition, young Lebanese drink more frequently than occasionally; $40 \%$ of high school students and half of university students consume alcohol at least 1 to 2 days per week $[10,11]$. This is explained by the ease of access to alcohol [9]. However, the availability of alcohol in restaurants, cafes, bars, or pubs depends on the licensing of the on-site outlets according to the Lebanese laws and regulations (Decision no. 3210, issued in 1974). Also, policies regulating the quantities of alcohol-containing products in supermarkets and other stores are also lacking in the country [12].

Alcohol consumption is the result of different factors including economic, environmental, cultural, biological, social and psychological aspects that interact together and affect the propensity for a human to use this substance. In fact, alcohol experience is an interaction between alcohol itself, the user and the surroundings [13]. Moreover, research has shown that patients with common mental disorders such as depression, anxiety, social anxiety, stress, difficulty in expressing emotions are at higher risk of alcohol use disorder [14]. Further, a high prevalence of insecure attachment styles (anxious-ambivalent and avoidant styles) was demonstrated among alcohol addicted inpatients compared to normative samples [15]. In addition, previous research has demonstrated the effect of stress and work fatigue on high alcohol consumption [16]. Alcohol use disorder could be considered an avoidance emotion and a coping strategy to alleviate stress [17]. Family risk for alcohol use disorder, low social and personal resources for coping with stress, and positive expectations of alcohol effects [18] are associated with individual vulnerability to alcohol use disorder. Furthermore, alcohol and alexithymia are highly related since alexithymic individuals do not feel comfortable at public events and would abuse alcohol to improve interpersonal behavior [19].

We realized that no studies have been conducted in Lebanon on factors associated with AUD. Therefore, the primary objective of our study was to assess independent factors associated with alcohol use disorder among a representative sample of the Lebanese population. Secondary objectives were to evaluate the association between groups of factors and clusters associated with AUD in the same sample. The results will allow us to compare facts from Lebanon with those obtained in Western countries.

\section{Methods}

\section{Sampling and data collection}

Participants were 789 community residents who agreed to enroll in this cross sectional study between January and December 2018, using a proportionate sample from the five Mohafazat in the country. The latter are divided into Caza (stratum), then villages. From a list provided by the Central Agency of Statistics in Lebanon, we chose two villages per Caza where the questionnaire was distributed randomly to the households, based on a random sampling technique to select the included house [20]. Questionnaires were completed via a face-to-face interview by clinical psychologists who were independent from the study. All individuals over the age of 18 were eligible to participate. Excluded were those with mental illness (schizophrenia and bipolar disorder) or dementia (as reported by a family member). The methodology used has been previously described elsewhere [21-41].

\section{Minimal sample size calculation}

According to Epi-info software, a minimal sample of 180 persons was needed based on a frequency of $6.2 \%$ of AUD among the general population according to previous findings [7], a 5\% error and a design effect of 2 .

\section{Questionnaire}

The questionnaire was in Arabic. In the first part, questions concerned the sociodemographic characteristics of each individual: age, gender, socioeconomic status (SES), marital status, education level and type of alcohol drunk. Then, the questionnaire included numerous validated scales that served our study purpose, which were also used in a previous paper as follows:

\section{The alcohol use disorders identification test (AUDIT)}

This test, composed of 10 items, is a tool to evaluate the use of alcohol, patterns when drinking alcohol, and problems alcohol-linked [42], which can be administered by a clinician or self-administered. Scores of 8 or above 
indicated hazardous/harmful alcohol use (high risk AUD), whereas scores below 8 indicated low AUD risk (Cronbach alpha $=0.885)$.

\section{Toronto alexithymia scale (TAS-20)}

In order to evaluate alexithymia, we used the TAS-20 scale [43], with the questions answers graded based on a five-point Likert scale $(1=$ strongly disagree to $5=$ strongly agree). Higher scores indicated higher alexithymia $($ Cronbach alpha $=0.778)$.

\section{Rosenberg self-esteem scale (RSES)}

Both negative and positive feelings of any individual can be assessed by the RSES 10 item scale [44]. The answers of the questions are graded based on a four-point Likert scale with 1 or strongly agree to 4 or strongly disagree. Higher scores are signs of greater self-esteem (Cronbach alpha $=0.733)$.

\section{Hamilton depression rating scale (HDRS)}

A validated Arabic version of the HDRS was used [45]. The first 17 items of the HDRS are scored and measure the severity of depressive symptoms [46]. Higher scores indicated higher depression (Cronbach alpha $=0.890$ ).

\section{Hamilton anxiety scale (HAM-A)}

A validated version of the HAM-A was used $[47,48]$. It is formed of fourteen items, ranged according to a fourpoint Likert scale with zero or no symptoms to four or very severe symptoms. Greater score values indicated higher levels of anxiety (Cronbach alpha $=0.898$ ).

\section{Evaluation of the three-dimensional work fatigue inventory (3D-WFI)}

Work-associated physical, mental and emotional fatigue are evaluated respectively using the 18-item 3D-WFI scale [49]. Questions' scoring ranked from 0 or never to 4 or every day. For all three studied factors, higher scores reflect greater levels of fatigue (Cronbach alpha for work fatigue were $0.823,0.667$ and 0.909 respectively).

\section{Columbia-suicide severity rating scale (C-SSRS)}

It is an assessment instrument that measures suicidal behavior and ideation. As for the scoring, 0 means that the ideation of suicide is absent, whereas scoring 1 or above indicates a possible presence of suicidal ideation [50] (Cronbach alpha $=0.762)$.

\section{The perceived stress scale (PSS)}

This scale is composed of ten items, which measures stress in the last month, with greater scores pointing out higher perceived stress (Cronbach alpha $=0.667$ ).

\section{Liebowitz social anxiety scale (LSAS)}

This scale features 24 items to assess performance anxiety and social situations based on a Likert scale from 0 to 3 . Higher scores reflect higher social fear and avoidance. The Cronbach's alpha values were for total score 0.954, for fear subscale 0.945 and for avoidance subscale 0.953 .

\section{The quick emotional intelligence self-assessment}

This scale assesses four subscales, emotional alertness, emotional control, social emotional awareness and relationship management. In all four domains, higher scores show higher emotional intelligence [51]. The Cronbach's alpha values for the above mentioned subscales were $0.823,0.888,0.902,0.908$ respectively.

The questionnaire scales underwent both forward and back translations. At first, a mental health specialist translated all scales from English to Arabic. Then another mental health expert performed a translation from Arabic back to English. No significant differences were found between both English versions; therefore, the Arabic questionnaire was used as is.

\section{Statistical analyses}

The statistical data analysis was conducted using the 23rd version of the SPSS software. When comparing two means we used the independent-sample t-test, whereas the analysis of variance (ANOVA) was used to compare three or more means. Bonferroni adjustment was used for ANOVA post hoc tests of between groups comparison. Chi-2 was used for categorical variables' comparisons.

As for the reduction of data, factor and cluster analyses were used. Factor analysis was executed to detect groups of risk factors that go together and are associated with AUD in the sample. The latter adequacy with Bartlett's Chi-square test of sphericity and Kaiser-MeyerOlkin (KMO) index was confirmed as a preliminary step. Factors were extracted using a principal component analysis method and a promax rotation since factors were correlated. In this study, we retained factors with an Eigenvalue $>1$. Items with factor loading values $>0.4$ were taken as loading on a factor. Reliability was assessed using Cronbach's alpha values. Second, we executed a cluster analysis with the identified factor scores to reflect profiles of participants, using the K-mean method. Analysis allowed for 10 iterations centering results on zero and convergence was only reached using a three-cluster structure, i.e., three different profiles.

Finally, several multivariable analyses were conducted using variables, factors and profiles: A backward logistic regression was conducted taking the dichotomous alcohol use disorder variable (low vs. high risk) as the dependent variable. Three stepwise linear regressions were conducted, taking the AUDIT result as the dependent variable. All variables/factors/clusters that showed a $p<0.1$ in 
the bivariate analysis were taken as independent variables in the model, including sociodemographic and psychological variables. In all cases, a $p<0.05$ was considered significant.

\section{Results}

Of the 950 questionnaires distributed, 789 (83.05\%) were completed and collected. A significantly higher proportion of male participants compared to females (58.8 vs $38.1 \% ; p<0.001$ ), with a primary level of education compared to all other categories $(\mathrm{p}<0.001)$ and widowed compared to all other marital statuses $(p=0.001)$ had high risk AUD. A significantly lower mean of number of kids was found in participants at high risk of AUD compared to low risk participants $(0.62$ vs. $0.91 ; p=0.008)$ (Table 1). The post-hoc analysis results showed that a significantly higher percentage of participants with a primary level of education had high risk AUD compared to those with secondary $(76.9 \%$ vs $48.2 \%$; $p=0.002)$, university $(76.9 \%$ vs $44.2 \% ; p<0.001)$ and higher university (76.9\% vs $43.8 \%$ ) levels of education. Moreover, a significantly higher percentage of participants with a

Table 1 Sociodemographic characteristics of the sample population

\begin{tabular}{|c|c|c|c|}
\hline & \multicolumn{2}{|c|}{ Alcohol use disorder } & \multirow[t]{3}{*}{$p$-value } \\
\hline & Low risk & High risk & \\
\hline & Frequency (\%) & Frequency (\%) & \\
\hline \multicolumn{4}{|l|}{ Gender } \\
\hline Male & $173(41.2 \%)$ & $247(58.8 \%)$ & \multirow[t]{2}{*}{$<0.001$} \\
\hline Female & $216(61.9 \%)$ & $133(38.1 \%)$ & \\
\hline \multicolumn{4}{|l|}{ Education level } \\
\hline Illiterate & $4(33.3 \%)$ & $8(66.7 \%)$ & \multirow[t]{6}{*}{$<0.001$} \\
\hline Primary & $9(23.1 \%)$ & $30(76.9 \%)$ & \\
\hline Complementary & $18(34.6 \%)$ & $34(65.4 \%)$ & \\
\hline Secondary & $57(51.8 \%)$ & $53(48.2 \%)$ & \\
\hline University & $258(55.8 \%)$ & $204(44.2 \%)$ & \\
\hline higher education & $36(56.3 \%)$ & $28(43.8 \%)$ & \\
\hline \multicolumn{4}{|l|}{ Socioeconomic status } \\
\hline$<1000 \$$ & $195(51.9 \%)$ & $181(48.1 \%)$ & \multirow[t]{3}{*}{0.446} \\
\hline $1000-2000 \$$ & $126(48.8 \%)$ & $132(51.2 \%)$ & \\
\hline$>2000 \$$ & $47(45.2 \%)$ & $57(54.8 \%)$ & \\
\hline \multicolumn{4}{|l|}{ Marital status } \\
\hline Single & $257(52.9 \%)$ & $229(47.1 \%)$ & \multirow[t]{5}{*}{0.001} \\
\hline Married & $124(52.8 \%)$ & $111(47.2 \%)$ & \\
\hline Widowed & $3(15.8 \%)$ & $16(84.2 \%)$ & \\
\hline \multirow[t]{2}{*}{ Divorced } & $8(26.7 \%)$ & $22(73.3 \%)$ & \\
\hline & Mean \pm SD & Mean \pm SD & \\
\hline Age (in years) & $30.27 \pm 13.14$ & $30.33 \pm 11.90$ & 0.945 \\
\hline Number of kids & $0.91 \pm 1.62$ & $0.62 \pm 1.28$ & 0.008 \\
\hline
\end{tabular}

complementary education level had high risk AUD compared to those with secondary $(65.4 \%$ vs $48.2 \% 1 p=0.04)$, university (65.4\% vs $44.2 \% ; p=0.004)$ and higher university $(65.4 \%$ vs $43.8 \% ; p=0.02)$ education levels. Finally, a significantly higher percentage of widowed $(84.2 \%$ vs $47.1 \% ; p=0.002)$ and divorced $(73.3 \%$ vs $47.1 \% ; p=$ 0.005) participants had high risk AUD compared to single ones, whereas a significantly higher percentage of widowed $(84.2 \%$ vs $47.2 \% ; p=0.002)$ and divorced (73.3\% vs $47.2 \% 1 \quad p=0.007$ ) participants had high risk AUD compared to married ones.

\section{Bivariate analysis}

Higher alexithymia (54.55 vs. $49.73 ; p<0.001$ ), depression ( 17.31 vs. $8.00 ; p<0.001)$, anxiety ( 17.58 vs. 10.90 ; $p<0.001)$, perceived stress (19.37 vs. $17.64 ; p<0.001)$, emotional work fatigue (20.32 vs. $15.29 ; p<0.001)$, physical work fatigue $(18.57$ vs. $17.52 ; \mathrm{p}<0.001)$, mental work fatigue $(17.63$ vs $14.05 ; p<0.001)$ and suicidal ideation (1.00 vs. $0.17 ; p=0.001)$ were significantly found in patients at high risk AUD compared to those at low risk. Moreover, higher emotional awareness, emotional management, social emotional awareness and relationship management scores were found in patients with low risk AUD compared to those at high risk (Table 2).

\section{Factor analysis}

All items of the study instrument could be extracted and used in the analyses. The total items converged over a solution of 4 factors: Factor one indicates mental wellbeing (i.e. low emotional work fatigue and high emotional intelligence); Factor two indicates psychological distress

Table 2 Association between the alcohol use disorder scale score and all other scales

\begin{tabular}{lllll}
\hline & \multicolumn{2}{l}{ Alcohol dependence } & p-value \\
\cline { 2 - 3 } & Low risk & High risk & \\
& Mean \pm SD & Mean \pm SD & \\
\hline Alexithymia Scale (TAS-20) & $49.73 \pm 10.01$ & $54.55 \pm 10.30$ & $<0.001$ \\
Depression score (HAM-D) & $8.00 \pm 7.93$ & $17.31 \pm 10.71$ & $<0.001$ \\
Anxiety score (HAM-A) & $10.90 \pm 9.40$ & $17.58 \pm 9.69$ & $<0.001$ \\
Perceived stress scale (PSC) & $17.64 \pm 6.14$ & $19.37 \pm 5.58$ & $<0.001$ \\
Liebowitz social anxiety scale & $36.58 \pm 24.77$ & $42.75 \pm 20.59$ & $<0.001$ \\
Emotional awareness & $20.32 \pm 7.71$ & $17.68 \pm 7.00$ & 0.097 \\
Emotional management & $22.25 \pm 8.82$ & $17.54 \pm 7.13$ & $<0.001$ \\
Social Emotional awareness & $23.81 \pm 8.80$ & $19.59 \pm 7.64$ & 0.005 \\
Relationship management & $23.69 \pm 9.15$ & $19.35 \pm 7.87$ & $<0.001$ \\
Emotional work fatigue & $15.29 \pm 9.73$ & $20.32 \pm 11.12$ & $<0.001$ \\
Physical work fatigue & $17.52 \pm 8.19$ & $18.57 \pm 8.36$ & $<0.001$ \\
Mental work fatigue & $14.05 \pm 7.97$ & $17.63 \pm 9.51$ & $<0.001$ \\
Suicidal ideation score & $0.17 \pm 0.73$ & $1.00 \pm 1.50$ & 0.001 \\
\hline
\end{tabular}


(i.e. high mental and physical work fatigue, high stress and alexithymia); Factor three indicates mood/affective dysfunction (i.e. high suicidal ideation, high depression and high anxiety); Factor four indicates social dysfunction (i.e. low self-esteem and high social phobia) explaining a total of $65.61 \%$ of the variance $(\mathrm{KMO}=0.832$; Bartlett's test of sphericity $p<0.001$ ) (Table 3 ).

\section{Profiles of participants}

Based on the 4 factors, a cluster analysis derived three mutually exclusive clusters. Cluster number one formed $45.4 \%$ of the sample and assembled people with psychological difficulties (work fatigue and high stress, high emotional work fatigue and low emotional intelligence, low self-esteem, high social phobia, high alexithymia); Cluster number two formed $34.4 \%$ of the sample and assembled people with high wellbeing (low suicidal ideation, low emotional work fatigue, depression and anxiety, high emotional intelligence, high self-esteem and low social phobia); whereas cluster 3 formed $20.2 \%$ of the sample and represented people with mental dysfunction (high anxiety and depression, high suicidal ideation, low self-esteem and high social phobia, low emotional intelligence, high emotional work fatigue) (Table 4).

\section{Multivariable analyses}

The results of a first backward logistic regression, taking the dichotomous AUDIT variable as the dependent variable

Table 3 Pattern loading of the major factor solutions after promax rotation, without taking the alcohol use disorders (AUDIT score) among these factors

\begin{tabular}{lcccc}
\hline & Factor 1 & Factor 2 & Factor 3 & Factor 4 \\
\hline High social emotional awareness & 0.881 & & & \\
High relationship management & 0.868 & & \\
High emotional management & 0.831 & & \\
High emotional awareness & 0.813 & & \\
Low emotional work fatigue & 0.706 & & \\
High physical work fatigue & & 0.826 & \\
High perceived stress & & 0.814 & \\
High alexithymia Scale (TAS-20) & & 0.744 & & \\
High mental work fatigue & & 0.594 & & \\
High suicidal ideation & & & 0.867 & \\
High depression score (HAM-D) & & & 0.833 & \\
High anxiety score (HAM-A) & & & 0.658 & \\
Low Rosenberg self-esteem & & & & 0.863 \\
High Liebowitz total score & & & & 0.452 \\
\hline
\end{tabular}

Factor $1=$ mental wellbeing (i.e. high emotional intelligence and low emotional work fatigue; Factor $2=$ psychological distress (i.e. high physical and mental work fatigue, high stress and high alexithymia; Factor $3=$ mood/ affective dysfunction (i.e. high suicidal ideation, high depression and high anxiety; Factor 4 = social dysfunction (i.e. low self-esteem and high social phobia) and the sociodemographic characteristics as independent variables, showed that being divorced $(\mathrm{ORa}=6.723$; $\mathrm{CI}$ 1.379-32.784; $p=0.018$ ) was correlated with higher AUD risk in a significant way. Being a female $(\mathrm{ORa}=0.431$; CI $0.308-0.605 ; p<0.001)$, having a higher number of kids $(\mathrm{ORa}=0.656 ; \mathrm{CI} 0.526-0.819 ; p<0.001)$ and a high university degree $(\mathrm{ORa}=0.204 ; \mathrm{CI} 0.048-0.860 ; p=0.03)$ were significantly associated with lower AUD risk.

The multivariable analyses results in models 2 to 5 were adjusted for the sociodemographic characteristics. A second backward logistic regression, taking the dichotomous AUDIT variable as the dependent variable, showed that higher alexithymia $(\mathrm{ORa}=1.030$; CI 1.009 $1.051 ; p=0.004)$, depression $(\mathrm{ORa}=1.076$; CI 1.050 $1.103 ; p<0.001)$ and suicidal ideation $(\mathrm{ORa}=1.253 ; \mathrm{CI}$ $1.026-1.531 ; p=0.027$ ) were significantly associated with higher AUD risk. Finally, higher emotional management $(\mathrm{ORa}=0.962 ;$ CI $0.937-0.988 ; p=0.005)$ was significantly associated with lower AUD risk.

A third linear regression, taking the continuous AUDIT score as the dependent variable, showed that depression (Beta $=0.282 ;$ CI $0.220-0.344 ; \quad p<0.001$ ), alexithymia (Beta $=0.146$; CI $0.093-0.200 ; p<0.001)$ and suicidal ideation (Beta $=0.855$; CI 0.385-1.325; $p<0.001$ ) were linked to higher AUDIT scores, while higher emotional management (Beta $=-0.079$; CI $-0.150--0.008 ; p=0.03$ ) was associated with lower AUDIT scores.

Fourth linear regression, taking the continuous AUDIT score as the dependent variable and the factors obtained in the factor analysis as independent variables, showed that Factor 2 (Psychological distress) (Beta $=1.107$; CI $0.496-1.719 ; p<0.001)$ and Factor 3 (mood/affective dysfunction) (Beta $=3.330$; CI 2.672-3.989; $p<0.001$ ) were associated with higher AUDIT scores, whereas Factor 1 (mental wellbeing) (Beta $=-0.817$; CI $-1.417--0.217 ; p=$ 0.008 ), was associated with lower AUDIT scores.

The fifth linear regression was obtained with the continuous AUDIT score chosen as the dependent variable while the obtained clusters were taken as independent variables. The regression showed that people with psychological difficulties (cluster 1) (Beta $=5.547$; CI 4.430$6.663 ; p<0.001$ ) and people in distress (cluster 3) (Beta $=7.455$; CI $5.945-8.965 ; p<0.001)$ were associated with higher AUDIT scores compared to participants with high wellbeing (cluster 2) (Table 5).

The results of the logistic regressions using the ENTER method for all models can be found in Supplementary Table 1.

\section{Discussion}

In Lebanon, there have been no studies that aimed to evaluate factors associated with alcohol use disorder among its population. 
Table 4 Classification of participants in the study sample by cluster analysis using the categories factor scoring

\begin{tabular}{llll}
\hline & $\begin{array}{l}\text { Cluster 1 N=269 } \\
(45.4 \%)\end{array}$ & $\begin{array}{l}\text { Cluster 2N=204 } \\
(34.4 \%)\end{array}$ & $\begin{array}{l}\text { Cluster 3 N=120 } \\
(20.2 \%)\end{array}$ \\
\hline Factor 1: High emotional intelligence \& low emotional work fatigue & -0.34 & 0.92 & -0.79 \\
$\begin{array}{l}\text { Factor 2: High physical and mental work fatigue, high stress \& } \\
\text { high alexithymia }\end{array}$ & 0.53 & -0.57 & -0.23 \\
Factor 3: High suicidal ideation \& high depression and anxiety & 0.31 & -0.86 & 0.76 \\
Factor 4: low self-esteem \& high social phobia. & 0.71 & -0.42 & -0.87 \\
\hline
\end{tabular}

Cluster 1 = People with psychological difficulties (low self-esteem, high social phobia, high alexithymia, high physical and mental work fatigue and high stress, low emotional intelligence and high emotional work fatigue); cluster 2 =People with high wellbeing (high emotional intelligence and low emotional work fatigue, with low suicidal ideation, low depression and anxiety, high self-esteem and low social phobia); cluster $3=$ People in distress (High suicidal ideation, high depression and anxiety, with low self-esteem \& high social phobia)

\section{Independent factors associated with AUD}

Our results showed that work fatigue, as indicated by high scores of physical and mental fatigue at work, was associated with a higher risk of alcohol use disorder, consistent with previous studies [52-54]. Psychosocial stress at work, characterized by an imbalance between efforts spent in terms of psychological and physical load and reward (such as money, esteem and career opportunities) [55], is a risk factor for alcohol use disorder [56]. In fact, heavy workload or demanding jobs make workers with little personal and social resources prone to both work fatigue and addictive behavior. At the neurobiological level, work fatigue and alcohol use disorder are associated because of the link between stress and alcohol consumption [57]. Alcohol appears to be a stress reliever when craving for stress alleviation, this process involves both intracellular and dopaminergic extracellular mechanisms [57].

Our results also showed high alcohol consumption in response to a higher number of stressors. Alcoholism, alcohol abuse, heavy drinking and alcohol dependence were previously shown to be directly related to stressful living situations and persistent stressors [58]. However, while some studies have reported positive associations, others have found negative associations [59, 60]. Alcohol is an effective anxiolytic and serves as a coping strategy against stress and work fatigue [61] .

Regarding the sociodemographic characteristics and their relationship with AUD, married individuals had lower AUDIT scores. This may be due to the tight connections among each family and solidarity between different generations, which is one of the fundamental qualities of Middle Eastern/Arab countries. The executed research also found that female gender was associated with lower AUDIT scores. As previous studies showed, men were more prone to alcoholism than women [62-64]. This could be related to the cultural or religious norms and values that make women less comfortable reporting embarrassing or prohibited behaviors.

\section{Factors associated with AUD}

Our results demonstrated a negative relationship between emotional intelligence, emotional work fatigue (Factor 1) and alcohol use disorders. One possible hypothesis is that when individuals are more capable of managing and controlling their own emotions, and to a certain extent the emotions of others, they would be less likely to report feeling alienated and distant from others, and therefore do not have addictive behaviors such as alcohol. To our knowledge, no studies have revealed the correlation between these factors at the same time. Based on our findings, emotional intelligence was lower in participants with high AUD risk compared to those at low risk, consistent with previous studies [65-67]. There is evidence that those who become addicted to alcohol are not able to understand and talk about their feelings [66]. They use alcohol to relax and remove their ambiguous and unknown stresses and discomforts.

Our results showed that psychological difficulties (Factor 2), including high alexithymia, high stress, high physical and mental work fatigue, were associated with higher AUD risk. A higher alexithymia score, as shown by a higher TAS score, was associated with a higher AUD risk. Our study corroborates the findings of a previous study where higher self-reporting of alcohol and nicotine cravings and stress were associated with difficulties in recognizing and expressing emotions [68]. Furthermore, alcohol helps relieve stressful conditions and improves interpersonal activity in people with alexithymia [69]. These people consume alcohol to become more outgoing, sociable and self-assured, and find it easier to express their feeling after alcohol consumption [19]. Individuals with a high alexithymia, and higher overall work fatigue scores [70] are often associated with low work-related interest, complications in interpersonal relationships, and a poor physical situation, with higher score of perceived stress, and use alcohol as an escape from stress and confused emotions [71].

Positive and significant correlation was shown between mood/affective disorders (Factor 3: high suicidal thoughts, high anxiety and depression) and higher AUDIT scores. Alcoholism can have negative effects on 
Table 5 Multivariable analysis

Model 1: Logistic regression taking the dichotomous alcohol use disorder scale score (low vs. high risk) as the dependent variable and the sociodemographic characteristics as independent variables.

\begin{tabular}{|c|c|c|c|c|}
\hline \multirow{2}{*}{\multicolumn{2}{|c|}{ OR }} & \multirow[t]{2}{*}{$p$-value } & \multicolumn{2}{|c|}{ Confidence interval } \\
\hline & & & Lower Bound & Lower Bound \\
\hline Gender (females vs males ${ }^{\mathrm{a}}$ ) & 0.431 & $<0.001$ & 0.308 & 0.605 \\
\hline Divorced vs single $\mathrm{a}^{\mathrm{a}}$ & 6.723 & 0.018 & 1.379 & 32.784 \\
\hline Number of kids & 0.656 & $<0.001$ & 0.526 & 0.819 \\
\hline Secondary education level vs illiterate ${ }^{a}$ & 0.272 & 0.083 & 0.062 & 1.185 \\
\hline University education level vs illiterate ${ }^{a}$ & 0.204 & 0.030 & 0.048 & 0.860 \\
\hline
\end{tabular}

Variables entered: Gender, Marital status, number of kids, education level

Model 2: Logistic regression taking the dichotomous alcohol use disorder scale score (low vs. high risk) as the dependent variable.

$\begin{array}{lllll}\text { Gender (females vs males }{ }^{\mathrm{a}} \text { ) } & 0.460 & <0.001 & 0.305 & 0.694 \\ \text { Alexithymia Scale (TAS-20) } & 1.030 & 0.004 & 1.009 & 1.051 \\ \text { Depression score (HAM-D) } & 1.076 & <0.001 & 1.050 & 1.103 \\ \text { Emotional management } & 0.962 & 0.005 & 0.937 & 0.988 \\ \text { Suicidal ideation score } & 1.253 & 0.027 & 1.026 & 1.531 \\ \text { Number of kids } & 0.863 & 0.037 & 0.752 & 0.991\end{array}$

Variables entered: Gender, Marital status, number of kids, education level, TAS_20, HAMD score, HAMA score, PSC score, Liebowitz score, Emotional awareness score, Emotional management score, Social emotional awareness score, Relationship management score, MBI - Emotional exhaustion, MBI - Personal accomplishment, MBI - Depersonalization, Suicidal ideation score.

Model 3: Linear regression taking the continuous AUDIT score as the dependent variable and all the scales as independent variables.

\begin{tabular}{llllll} 
& Unstandardized Beta & Standardized Beta & $p$-value & \multicolumn{2}{c}{$\begin{array}{c}\text { Confidence interval } \\
\text { Lower Bound }\end{array}$} \\
& & & & Upper Bound \\
Depression score (HAM-D) & 0.282 & 0.354 & $<0.001$ & 0.220 & 0.344 \\
Alexithymia Scale (TAS-20) & 0.146 & 0.189 & $<0.001$ & 0.093 & 0.200 \\
Suicidal ideation score & 0.855 & 0.134 & $<0.001$ & 0.385 & 1.325 \\
Emotional management & -0.079 & -0.078 & 0.030 & -0.150 & -0.008 \\
Gender (females vs males ${ }^{\mathrm{a}}$ ) & -2.647 & -0.160 & $<0.001$ & -3.771 & -1.523 \\
Secondary education vs illiterate $^{\mathrm{a}}$ & -2.476 & -0.103 & 0.012 & -4.415 & -0.538 \\
University education vs illiterate $^{a}$ & -2.579 & -0.148 & $<0.001$ & -4.024 & -1.134 \\
Intermediate vs low $^{\text {a SES }}$ & 1.167 & 0.067 & 0.050 & 0.001 & 2.333
\end{tabular}

Variables entered: Age, Gender, SES, education level, TAS_20, HAMD score, HAMA score, PSC score, Liebowitz score, Emotional awareness score, Emotional management score, Social emotional awareness score, Relationship management score, MBI - Emotional exhaustion, MBI - Personal accomplishment, $\mathrm{MBI}$ - Depersonalization, Suicidal ideation score.

a SES = socioeconomic status (Reference = low socioeconomic status).

Model 4: Linear regression taking the continuous AUDIT score as the dependent variable and four factors obtained in the factor analysis as independent variables.

$\begin{array}{llllll}\text { Mental Wellbeing (Factor 1) } & -0.817 & -0.099 & 0.008 & -1.417 & -0.217 \\ \text { Psychological distress (Factor 2) } & 1.107 & 0.136 & <0.001 & 0.496 & 1.719 \\ \text { Mood/affective dysfunction (Factor 3) }_{\text {Gender (females vs males }}^{\mathrm{a} \text { ) }} & 3.330 & 0.398 & <0.001 & 2.672 & 3.989 \\ \text { Secondary education vs illiterate }^{\mathrm{a}} & -2.613 & -0.158 & <0.001 & -3.764 & -1.462 \\ \text { University education vs illiterate }^{\mathrm{a}} & -2.505 & -0.105 & 0.014 & -4.507 & -0.503 \\ \end{array}$

Factor 1 = mental wellbeing (i.e. high emotional intelligence and low emotional work fatigue; Factor $2=$ psychological distress (i.e. high physical and mental work fatigue, high stress and high alexithymia; Factor $3=$ mood/affective dysfunction (i.e. high suicidal ideation, high depression and high anxiety; Factor $4=$ social dysfunction (i.e. low self-esteem and high social phobia).

Variables entered in the model: Factor 1, Factor 2, Factor 3, factor 4, Age, Gender, SES, education level.

Model 5: Linear regression taking the continuous AUDIT score as the dependent variable and the three clusters as independent variables.

People with psychological difficulties (Cluster 1) $\quad 5.547 \quad 0.325 \quad<0.001 \quad 4.430 \quad 6.663$ 
Table 5 Multivariable analysis (Continued)

\begin{tabular}{llllll}
\hline People in distress (Cluster 3) & 7.455 & 0.323 & $<0.001$ & 5.945 & 8.965 \\
Gender (Male ${ }^{\mathrm{a}}$ vs. Female) & -3.011 & -0.184 & $<0.001$ & -4.036 & -1.985 \\
Secondary education vs illiterate $^{\mathrm{a}}$ & -2.461 & -0.104 & 0.008 & -4.265 & -.657 \\
University education vs illiterate $^{\mathrm{a}}$ & -3.045 & -0.175 & $<0.001$ & -4.392 & -1.698 \\
Divorced vs. single $^{\mathrm{a}}$ & 5.047 & 0.118 & $<0.001$ & 2.397 & 7.698 \\
Widowed vs. single $^{\mathrm{a}}$ & 4.962 & 0.091 & 0.004 & 1.545 & 8.379
\end{tabular}

Variables entered in the model: cluster 1, cluster 2, cluster 3, Age, Gender, SES, education level

Cluster 1 = People with psychological difficulties (low self-esteem, high social phobia, high alexithymia, high physical and mental work fatigue and high stress, low emotional intelligence and high emotional work fatigue); cluster $2=$ People with high wellbeing (high emotional intelligence and low emotional work fatigue, with low suicidal ideation, low depression and anxiety, high self-esteem and low social phobia); cluster $3=$ People in distress (High suicidal ideation, high depression and anxiety, with low self-esteem \& high social phobia).

Reference group

mental status, and is often associated with mood disorders [72]. In fact, AUD can intensify impulsivity and aggravate those symptoms by stimulating the thoughts of hopelessness and sadness. In a recent review, the reciprocal association was demonstrated, with mood disorders being precursors of alcoholism [1]. Actually, this comorbidity can be a cyclic process [73, 74]. According to Watts, most individuals with mood disorders abuse alcohol in search of pleasure and disinhibition or for the reduction of cognitive, emotional and behavioral symptoms of depression [75]. However, the state of intoxication induced by alcohol abuse can increase impulsivity and promote feelings and thoughts of sadness, thus, worsening mood disorder symptoms [75]. Similarly, anxiety was prevalent in people with AUD. Dangerous alcohol use, refusal or increased dropout rates of AUD treatment was associated with a concurrent diagnosis of anxiety [76, 77]. Furthermore, our results confirm that high rates of suicide are associated with higher AUDIT scores. The results of a meta-analysis demonstrated that the risk of suicidal ideation, suicide attempts, and suicide was increased by $2-3$ times by AUD [78], which is considered a significant predictor of suicide [78].

Besides, the attained data showed an interconnection between social dysfunction (Factor 4; low self-esteem and high social phobia) and high risk of AUD. Selfesteem plays a major role in social anxiety disorder [79]; while lowered self-esteem may put the individual at risk of later social anxiety, having an anxiety disorder can also make him feel worse about himself. Controversial results were found between social anxiety and alcohol use, with some findings showing a positive association [80-83], while others showed no relationship [84]. One predominant mechanism suggested that lower levels of tension and stress are the main link between social anxiety, self-esteem and alcohol use [85]. According to this model (tension reduction hypothesis), alcohol acts as a negative reinforcer to reduce social stress and anxiety $[84,86]$.
Finally, the sample was categorized into three groups/ clusters. The present results were reasonable since Lebanese are vulnerable to mental disorders for many reasons: a study conducted in 2003 has found that approximatively $50 \%$ of the population in Lebanon was traumatized due to the war [87]. The unstable political condition, the history of wars and terrorist attacks [88] and the absence of a clean environment [89] in Lebanon would consequently contribute to the increase in mental disorders among this population. Another contributor is the increased flow of Syrian refugees that decreased employment rates [89] and xenophobic mindsets among the Lebanese [90]. This is concordant with how the public eye looks at mental illness as a mark of disgrace [91], and the undeclared forbiddance to seek a treatment from a healthcare professional for such disorders [92].

\section{Clinical implications}

Alcohol is a psychoactive substance, legally produced and sold, the production and marketing of which can be easily controlled and regulated by local authorities through the serious implementation of laws and policies. Further, recognition of risk factors is the starting point for identifying and preventing AUD among vulnerable people and for treating symptoms already experienced. It is essential to bring attention towards factors associated with alcohol use disorder and prevent/treat them.

\section{Limitations}

Our study is cross-sectional, therefore, causation can't be inferred. Some scales translated into the Arabic language have not been validated yet. Recall bias might be present since the study is retrospective and can lead to the overestimation of effects for some known factors recognized to be associated with alcohol use disorder. Participants might have misapprehended few questions, symptoms may have been either over/under evaluated. These two inconveniences might present a major source 
of information bias. The refusal rate is also a main reason behind the selection bias.

\section{Conclusion}

AUD seems to be influenced by several factors among the Lebanese population, including stress, anxiety and work fatigue. Healthcare professionals should spread awareness to reduce the prevalence of these factors. Screening and periodic monitoring of alcohol consumption are recommended, as well as therapeutic intervention among the population.

\section{Supplementary information}

Supplementary information accompanies this paper at https://doi.org/10. 1186/s12889-020-8345-1.

Additional file 1. Supplementary Table 1: Multivariable analysis using the ENTER method for all models.

\section{Abbreviations}

3D-WFI: Evaluation of the Three-Dimensional Work Fatigue Inventory; AUDIT: Alcohol Use Disorders Identification Test; C-SSRS: Columbia-Suicide Severity Rating Scale; HAD: Hazardous Alcohol Drinking; HAM-A: Hamilton anxiety scale; HDRS: Hamilton depression rating scale; KMO: Kaiser-MeyerOlkin; LSAS: Liebowitz Social Anxiety Scale; PSS: Perceived Stress Scale; RSES: Rosenberg self-esteem scale; SES: Socioeconomic status; TAS: Toronto Alexithymia Scale; WHO: World Health Organization

\section{Acknowledgements}

We would like to thank as well all patients who agreed to participate in these studies.

\section{Authors' contributions}

$\mathrm{MA}$ and $\mathrm{KF}$ were responsible for the data collection and entry. SO and SH designed the study; SO drafted the manuscript; SH, CH and PS carried out the analysis and interpreted the results; HS edited the manuscript for English language and reviewed it for intellectual content; All authors reviewed the final manuscript and gave their consent. The author(s) read and approved the final manuscript

\section{Funding}

None.

\section{Availability of data and materials}

All data generated or analyzed during this study are not publicly available to maintain the privacy of the individuals' identities. The dataset supporting the conclusions is available upon request to the corresponding author.

\section{Ethics approval and consent to participate}

The protocol of the research was approved by the Psychiatric Hospital of the Cross Ethics and Research Committee as it was following the Hospital's Regulatory Research Protocol (HPC-013-2018). A written consent was obtained from each participant.

\section{Consent for publication}

Not applicable.

\section{Competing interests}

The authors declare that they have no competing interests.

\section{Author details}

${ }^{1}$ Research and Psychology departments, Psychiatric Hospital of the Cross, Jal Eddib, Lebanon. ${ }^{2}$ Faculty of Arts and Sciences, Holy Spirit University of Kaslik (USEK), Jounieh, Lebanon. ${ }^{3}$ INSPECT-LB: Institut National de Santé Publique, Epidémiologie Clinique et Toxicologie - Liban, Beirut, Lebanon. ${ }^{4}$ School of Pharmacy, Lebanese International University, Beirut, Lebanon. ${ }^{5}$ INSERM,
U1094, Tropical Neuroepidemiology, Limoges, France. ${ }^{6}$ Univ. Limoges, UMR 1094, Tropical Neuroepidemiology, Institute of Epidemiology and Tropical Neurology, GEIST, 87000 Limoges, France. ${ }^{7}$ Department of psychiatry, CH Esquirol, 87025 Limoges, France. ${ }^{8}$ Drug Information Center, Order of Pharmacists of Lebanon, Beirut, Lebanon. ${ }^{9}$ Faculty of Pharmacy, Lebanese University, Beirut, Lebanon. ${ }^{10}$ Faculty of Medicine, Lebanese University, Beirut, Lebanon. ${ }^{11}$ Faculty of Medicine and Medical Sciences, Holy Spirit University of Kaslik (USEK), Jounieh, Lebanon.

Received: 25 September 2019 Accepted: 11 February 2020

Published online: 18 February 2020

\section{References}

1. Littrell J. Understanding and treating alcoholism: volume I: an empirically based Clinician's handbook for the treatment of alcoholism: volume ii: biological, psychological, and social aspects of alcohol consumption and Abuse: Psychology Press; 2014.

2. Lim SS, Vos T, Flaxman AD, et al. A comparative risk assessment of burden of disease and injury attributable to 67 risk factors and risk factor clusters in 21 regions, 1990-2010: a systematic analysis for the global burden of disease study 2010. Lancet. 2012;380(9859):2224-60.

3. Popova S, Rehm J, Patra J, Zatonski W. Comparing alcohol consumption in central and eastern Europe to other European countries. Alcohol Alcohol. 2007:42(5):465-73.

4. Substance Abuse and Mental Health Services Administration (SAMHSA). Results from the 2015 National Survey on Drug Use and Health: Detailed Tables. Available from: https:/www.samhsa.gov/data/sites/default/files/ NSDUH-DetTabs-2015/NSDUH-DetTabs-2015/NSDUH-DetTabs-2015. htm\#tab5-6a.

5. Osman A. Substance abuse among patients attending a psychiatric hospital in Jeddah: a descriptive study. Ann Saudi Med. 1992;12(3):289-93.

6. Amin Y, Hamdi E, Ghubash R. Substance abuse consultation rates: experience from private practice in Dubai. Arab J Psychiatry. 1996;7(2):133-9.

7. Yazbek J-C, Haddad R, Bou Khalil R, et al. Prevalence and correlates of alcohol abuse and dependence in Lebanon: results from the Lebanese epidemiologic survey on alcohol (LESA). J Addict Dis. 2014;33(3):221-33.

8. Baasher T. The use of drugs in the Islamic world. Addiction. 1981;76(3):233-43.

9. Ghandour L, Afifi R, Fares S, El Salibi N, Rady A. Time trends and policy gaps: the case of alcohol misuse among adolescents in Lebanon. Subst Use Misuse. 2015;50(14):1826-39.

10. Zahlan L, Ghandour L, Yassin N, Afifi R, Martins SS. Double trouble: exploring the association between waterpipe tobacco smoking and the nonmedical use of psychoactive prescription drugs among adolescents. Drug Alcohol Depend. 2014;145:217-23.

11. Ghandour LA, El Sayed DS, Martins SS. Prevalence and patterns of commonly abused psychoactive prescription drugs in a sample of university students from Lebanon: an opportunity for cross-cultural comparisons. Drug Alcohol Depend. 2012;121(1-2):110-7.

12. Ghandour L, Chalak A, El-Aily A, et al. Alcohol consumption in the Arab region: what do we know, why does it matter, and what are the policy implications for youth harm reduction? Int J Drug Policy. 2016;28:10-33.

13. Andrade L, Silveira CM, Martins SS, Stor C, Wang Y-P, Viana MC. Padrões de consumo do álcool e problemas decorrentes do beber pesado episódico no Brasil. In: Álcool e suas conseqüências: abordagem multiconceitual; 2009. p. 1.

14. Kessler RC, Crum RM, Warner LA, Nelson CB, Schulenberg J, Anthony JC Lifetime co-occurrence of DSM-III-R alcohol abuse and dependence with other psychiatric disorders in the National Comorbidity Survey. Arch Gen Psychiatry. 1997;54(4):313-21.

15. Wedekind D, Bandelow B, Heitmann S, Havemann-Reinecke U, Engel KR, Huether G. Attachment style, anxiety coping, and personality-styles in withdrawn alcohol addicted inpatients. Subst Abuse Treat Prev Policy. 2013;8(1):1.

16. Ahola $\mathrm{K}$, Honkonen T, Pirkola S, et al. Alcohol dependence in relation to burnout among the Finnish working population. Addiction. 2006;101(10): $1438-43$.

17. Grunberg L, Moore S, Greenberg ES. Work stress and problem alcohol behavior: a test of the spillover model. J Organ Behav. 1998:487-502.

18. Cooper ML, Russell M, Skinner JB, Frone MR, Mudar P. Stress and alcohol use: moderating effects of gender, coping, and alcohol expectancies. J Abnorm Psychol. 1992;101(1):139-52. 
19. Thorberg FA, Young RM, Sullivan KA, et al. Alexithymia in alcohol dependent patients is partially mediated by alcohol expectancy. Drug Alcohol Depend. 2011;116(1-3):238-41.

20. The Central Agency of Statistics in Lebanon website. Available from: www. cas.gov.lb.

21. Haddad C, Hallit R, Akel M, et al. Validation of the Arabic version of the ORTO-15 questionnaire in a sample of the Lebanese population. Eat Weight Disord. 2019:1-10.

22. Haddad C, Obeid S, Akel M, et al. Correlates of orthorexia nervosa among a representative sample of the Lebanese population. Eat Weight Disord. 2019; 24(3):481-93.

23. Haddad C, Zakhour M, Akel M, et al. Factors associated with body dissatisfaction among the Lebanese population. Eat Weight Disord. 2019:1-13.

24. Khansa W, Haddad C, Hallit R, et al. Interaction between anxiety and depression on suicidal ideation, quality of life, and work productivity impairment: results from a representative sample of the Lebanese population. Perspect Psychiatr Care. 2019.

25. Lahoud N, Zakhour M, Haddad C, et al. Burnout and its relationships with alexithymia, stress, self-esteem, depression, alcohol use disorders, and emotional intelligence: results from a Lebanese cross-sectional study. J Nerv Ment Dis. 2019;207(8):642-50.

26. Obeid S, Fares K, Haddad C, et al. Construction and validation of the Lebanese fear of relationship commitment scale among a representative sample of the Lebanese population. Perspect Psychiatr Care. 2019.

27. Obeid S, Haddad C, Akel M, Fares K, Salameh P, Hallit S. Factors associated with the adults' attachment styles in Lebanon: the role of alexithymia, depression, anxiety, stress, burnout, and emotional intelligence. Perspect Psychiatr Care. 2019.

28. Obeid S, Sacre H, Haddad C, et al. Factors associated with fear of intimacy among a representative sample of the Lebanese population: the role of depression, social phobia, self-esteem, intimate partner violence, attachment, and maladaptive schemas. Perspect Psychiatr Care. 2019.

29. Obeid S, Akel M, Haddad C, et al. Factors associated with alexithymia among the Lebanese population: results of a cross-sectional study. BMC Psychol. 2019;7(1):80.

30. Saade $\mathrm{S}$, Hallit $\mathrm{S}$, Haddad $\mathrm{C}$, et al. Factors associated with restrained eating and validation of the Arabic version of the restrained eating scale among an adult representative sample of the Lebanese population: a crosssectional study. J Eat Disord. 2019;7(1):24.

31. Zeidan RK, Haddad C, Hallit R, et al. Validation of the Arabic version of the binge eating scale and correlates of binge eating disorder among a sample of the Lebanese population. J Eat Disord. 2019;7(1):40.

32. Zakhour M, Haddad C, Salameh P, et al. Impact of the interaction between alexithymia and the adult attachment styles in participants with alcohol use disorder. Alcohol. 2019.

33. Sfeir E, Haddad C, Salameh P, et al. Binge eating, orthorexia nervosa, restrained eating, and quality of life: a population study in Lebanon. Eat Weight Disord. 2019:1-14.

34. Obeid S, Haddad C, Zakhour M, et al. Correlates of self-esteem among the Lebanese population: a cross-sectional study. Psychiatr Danub. 2019;31(4): 429-39.

35. Fares K, Hallit S, Haddad C, Akel M, Khachan T, Obeid S. Relationship between cosmetics use, self-esteem, and self-perceived attractiveness among Lebanese women. J Cosmet Sci. 2019;70(1):47-56.

36. Hallit S, Sacre H, Haddad C, et al. Development of the Lebanese insomnia scale (LIS-18): a new scale to assess insomnia in adult patients. BMC Psychiatry. 2019;19(1):421.

37. Hallit S, Hajj A, Sacre H, et al. Impact of sleep disorders and other factors on the quality of life in general population: a cross-sectional study. J Nerv Ment Dis. 2019;207(5):333-9.

38. Obeid S, Saade $S$, Haddad $C$, et al. Internet addiction among Lebanese adolescents: the role of self-esteem, anger, depression, anxiety, social anxiety and fear, impulsivity, and aggression-a cross-sectional study. J Nerv Ment Dis. 2019;207(10):838-46.

39. Rahme C, Haddad C, Akel M, et al. Factors associated with violence against women in a representative sample of the Lebanese population: results of a cross-sectional study. Arch Womens Ment Health. 2020.

40. Rahme C, Haddad C, Akel M, et al. Does Stockholm syndrome exist in Lebanon? Results of a cross-sectional study considering the factors associated with violence against women in a Lebanese representative sample. J Interpers Violence. 2020;886260519897337.
41. Haddad C, Darwich MJ, Obeid S, et al. Factors associated with anxiety disorders among patients with substance use disorders in Lebanon: results of a cross-sectional study. Perspect Psychiatr Care. 2019.

42. Bohn MJ, Babor TF, Kranzler HR. The alcohol use disorders identification test (AUDIT): validation of a screening instrument for use in medical settings. J Stud Alcohol. 1995;56(4):423-32.

43. Bagby RM, Parker JD, Taylor GJ. The twenty-item Toronto alexithymia scale-I. item selection and cross-validation of the factor structure. J Psychosom Res. 1994;38(1):23-32.

44. Rosenberg M. Society and the adolescent self-image: Princeton university press; 1965.

45. Obeid S, Abi Elias Hallit C, Haddad C, Hany Z, Hallit S. Validation of the Hamilton Depression Rating Scale (HDRS) and sociodemographic factors associated with Lebanese depressed patients. Encephale. 2018.

46. Hamilton M. A rating scale for depression. J Neurol Neurosurg Psychiatry. 1960;23:56-62.

47. Hamilton M. The assessment of anxiety states by rating. $\mathrm{Br} J$ Med Psychol. 1959;32(1):50-5.

48. Hallit S, Haddad C, Hallit R, et al. Validation of the Hamilton Anxiety Rating Scale and State Trait Anxiety Inventory A and B in Arabic among the Lebanese population. Clin Epidemiol Glob Health. 2019.

49. Frone MR, Tidwell MO. The meaning and measurement of work fatigue: development and evaluation of the three-dimensional work fatigue inventory (3D-WFI). J Occup Health Psychol. 2015;20(3):273-88.

50. Nilsson ME, Suryawanshi S, Gassmann-Mayer C, Dubrava S, McSorley P, Jiang K. Columbia-suicide severity rating scale scoring and data analysis guide. CSSRS Scoring Version. 2013;2:1-13.

51. Mohapel P. The quick emotional intelligence self assessment. Accessed on, vol. 14; 2017.

52. Cunradi CB, Greiner BA, Ragland DR, Fisher JM. Burnout and alcohol problems among urban transit operators in San Francisco. Addict Behav. 2003:28(1):91-109.

53. Ogus ED, Greenglass ER, Burke RJ. Gender-role differences, work stress and depersonalization. J Soc Behav Pers. 1990;5(5):387.

54. Gorter RC, Eijkman MA, Hoogstraten J. Burnout and health among Dutch dentists. Eur J Oral Sci. 2000;108(4):261-7.

55. Siegrist J. Soziale Krisen Und Gesundheit Eine Theorie der Gesundheitsförderung Am Beispiel von Herz-Kreislauf-Risiken Im Erwerbsleben; 1996.

56. Siegrist J. Effort-reward imbalance at work and health. In: Historical and current perspectives on stress and health: Emerald Group Publishing Limited; 2002. p. 261-91.

57. Brady KT, Sonne SC. The role of stress in alcohol use, alcoholism treatment, and relapse. Alcohol Res Health. 1999;23(4):263.

58. Johnson $\mathrm{V}$, Pandina RJ. A longitudinal examination of the relationships among stress, coping strategies, and problems associated with alcohol use. Alcohol Clin Exp Res. 1993;17(3):696-702.

59. Romelsjö A, Lazarus NB, Kaplan GA, Cohen RD. The relationship between stressful life situations and changes in alcohol consumption in a general population sample. Addiction. 1991;86(2):157-69.

60. Temple MT, Fillmore KM, Hartka E, Johnstone B, Leino EV, Motoyoshi M. A meta-analysis of change in marital and employment status as predictors of alcohol consumption on a typical occasion. Addiction. 1991;86(10):1269-81.

61. Cappell H, Greeley J. Alcohol and tension reduction: an update on research and theory. In ht blane \& ke Leonard (eds.), Psychologicaltheories of drinking and alcoholism (pp. 15-54). NewYork: Guilford Press; 1987.

62. Hasin DS, Stinson FS, Ogburn E, Grant BF. Prevalence, correlates, disability, and comorbidity of DSM-IV alcohol abuse and dependence in the United States: results from the National Epidemiologic Survey on alcohol and related conditions. Arch Gen Psychiatry. 2007;64(7):830-42.

63. Andrews G, Henderson S, Hall W. Prevalence, comorbidity, disability and service utilisation: overview of the Australian National Mental Health Survey. Br J Psychiatry. 2001;178(2):145-53.

64. Holmila M, Raitasalo K. Gender differences in drinking: why do they still exist? Addiction. 2005;100(12):1763-9.

65. Goleman DP. Emotional intelligence: why it can matter more than IQ for character, health and lifelong achievement. New York: Bantam Books; 1995.

66. Ciarrochi J, Forgas JP, Mayer JD. Emotional intelligence in everyday life: a scientific inquiry: Psychology Press; 2001.

67. Janati Y, Musavi SA, Âzimi Lolaty H, et al. Investigating emotional intelligence and self esteem level among nursing and midwifery students of 
Mazandaran University of Medical Sciences in 2010. J Mazandaran Univ Med Sci. 2012;21(1):254-61.

68. Thorberg FA, Young RM, Sullivan KA, Lyvers M. Alexithymia and alcohol use disorders: a critical review. Addict Behav. 2009;34(3):237-45.

69. Finn PR, Martin J, Pihl RO. Alexithymia in males at high genetic risk for alcoholism. Psychother Psychosom. 1987:47(1):18-21.

70. Bratis D, Tselebis A, Sikaras C, et al. Alexithymia and its association with burnout, depression and family support among Greek nursing staff. Hum Resour Health. 2009;7(1):72.

71. Larsson MR, Bäckström M, MICHEL PO, LUNDH LG. The stability of alexithymia during work in a high-stress environment: a prospective study of Swedish peacekeepers serving in Kosovo. Scand J Psychol. 2010;51(4): $350-5$.

72. Grant BF, Stinson FS, Dawson DA, Chou SP, Ruan WJ, Pickering RP. Cooccurrence of 12-month alcohol and drug use disorders and personalitydisorders in the United States: results from the National Epidemiologic Survey on alcohol and RelatedConditions. Arch Gen Psychiatry. 2004;61(4):361-8.

73. Archie S, Kazemi AZ, Akhtar-Danesh N. Concurrent binge drinking and depression among Canadian youth: prevalence, patterns, and suicidality. Alcohol. 2012;46(2):165-72.

74. Timko C, Sutkowi A, Pavao J, Kimerling R. Women's childhood and adult adverse experiences, mental health, and binge drinking: The California Women's Health Survey. Subst Abuse Treat Prev Policy. 2008;3(1):15.

75. Watts M. Understanding the coexistence of alcohol misuse and depression. Br J Nurs. 2008;17(11):696-9.

76. Buckner JD, Timpano KR, Zvolensky MJ, Sachs-Ericsson N, Schmidt NB. Implications of comorbid alcohol dependence among individuals with social anxiety disorder. Depress Anxiety. 2008;25(12):1028-37.

77. Schneier FR, Foose TE, Hasin DS, et al. Social anxiety disorder and alcohol use disorder co-morbidity in the National Epidemiologic Survey on alcohol and related conditions. Psychol Med. 2010;40(6):977-88.

78. Darvishi N, Farhadi M, Haghtalab T, Poorolajal J. Alcohol-related risk of suicidal ideation, suicide attempt, and completed suicide: a meta-analysis. PLoS One. 2015;10(5):e0126870.

79. Hofmann SG. Cognitive factors that maintain social anxiety disorder: a comprehensive model and its treatment implications. Cogn Behav Ther. 2007;36(4):193-209.

80. Eggleston AM, Woolaway-Bickel K, Schmidt NB. Social anxiety and alcohol use: evaluation of the moderating and mediating effects of alcohol expectancies. J Anxiety Disord. 2004;18(1):33-49.

81. Ham LS, Bonin M, Hope DA. The role of drinking motives in social anxiety and alcohol use. J Anxiety Disord. 2007;21(8):991-1003.

82. Ham LS, Hope DA. Incorporating social anxiety into a model of college student problematic drinking. Addict Behav. 2005;30(1):127-50.

83. Stewart SH, Morris E, Mellings T, Komar J. Relations of social anxiety variables to drinking motives, drinking quantity and frequency, and alcoholrelated problems in undergraduates. J Ment Health. 2006;15(6):671-82.

84. Morris EP, Stewart SH, Ham LS. The relationship between social anxiety disorder and alcohol use disorders: a critical review. Clin Psychol Rev. 2005; 25(6):734-60

85. Conger JJ. Alcoholism: theory, problem and challenge. II. Reinforcement theory and the dynamics of alcoholism. Q J Stud Alcohol. 1956;17(2):296305.

86. Thomas $\mathrm{SE}$, Randall $\mathrm{CL}$, Carrigan MH. Drinking to cope in socially anxious individuals: a controlled study. Alcohol Clin Exp Res. 2003;27(12):1937-43.

87. Karam EG, Mneimneh ZN, Karam AN, et al. Prevalence and treatment of mental disorders in Lebanon: a national epidemiological survey. Lancet. 2006;367(9515):1000-6.

88. Cherri Z, González PA, Delgado RC. The Lebanese-Syrian crisis: impact of influx of Syrian refugees to an already weak state. Risk Manag Healthc Policy. 2016;9:165.

89. Turner BJ, Hollenbeak CS, Weiner M, Tang SS. A retrospective cohort study of the potency of lipid-lowering therapy and race-gender differences in LDL cholesterol control. BMC Cardiovasc Disord. 2011;11(1):58.

90. Obeid S, Haddad C, Salame W, Kheir N, Hallit S. Xenophobic attitudes, behaviors and coping strategies among Lebanese people toward immigrants and refugees. Perspect Psychiatr Care. 2019.

91. Abi Doumit C, Haddad C, Sacre H, et al. Knowledge, attitude and behaviors towards patients with mental illness: Results from a national Lebanese study. PLoS One. 2019;14(9).
92. Rayan A, Fawaz M. Cultural misconceptions and public stigma against mental illness among Lebanese university students. Perspect Psychiatr Care. 2018;54(2):258-65.

\section{Publisher's Note}

Springer Nature remains neutral with regard to jurisdictional claims in published maps and institutional affiliations.
Ready to submit your research? Choose BMC and benefit from:

- fast, convenient online submission

- thorough peer review by experienced researchers in your field

- rapid publication on acceptance

- support for research data, including large and complex data types

- gold Open Access which fosters wider collaboration and increased citations

- maximum visibility for your research: over $100 \mathrm{M}$ website views per year

At BMC, research is always in progress.

Learn more biomedcentral.com/submissions 